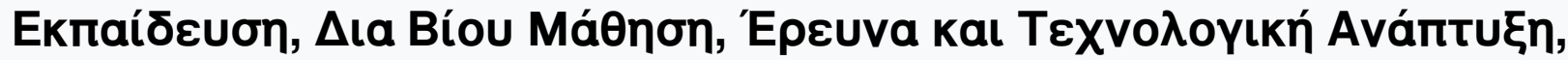

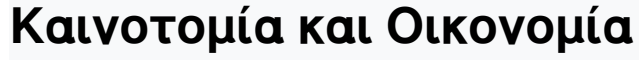

Tóp. 1 (2016)

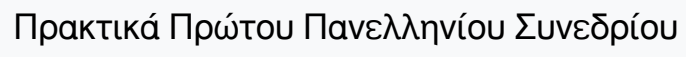

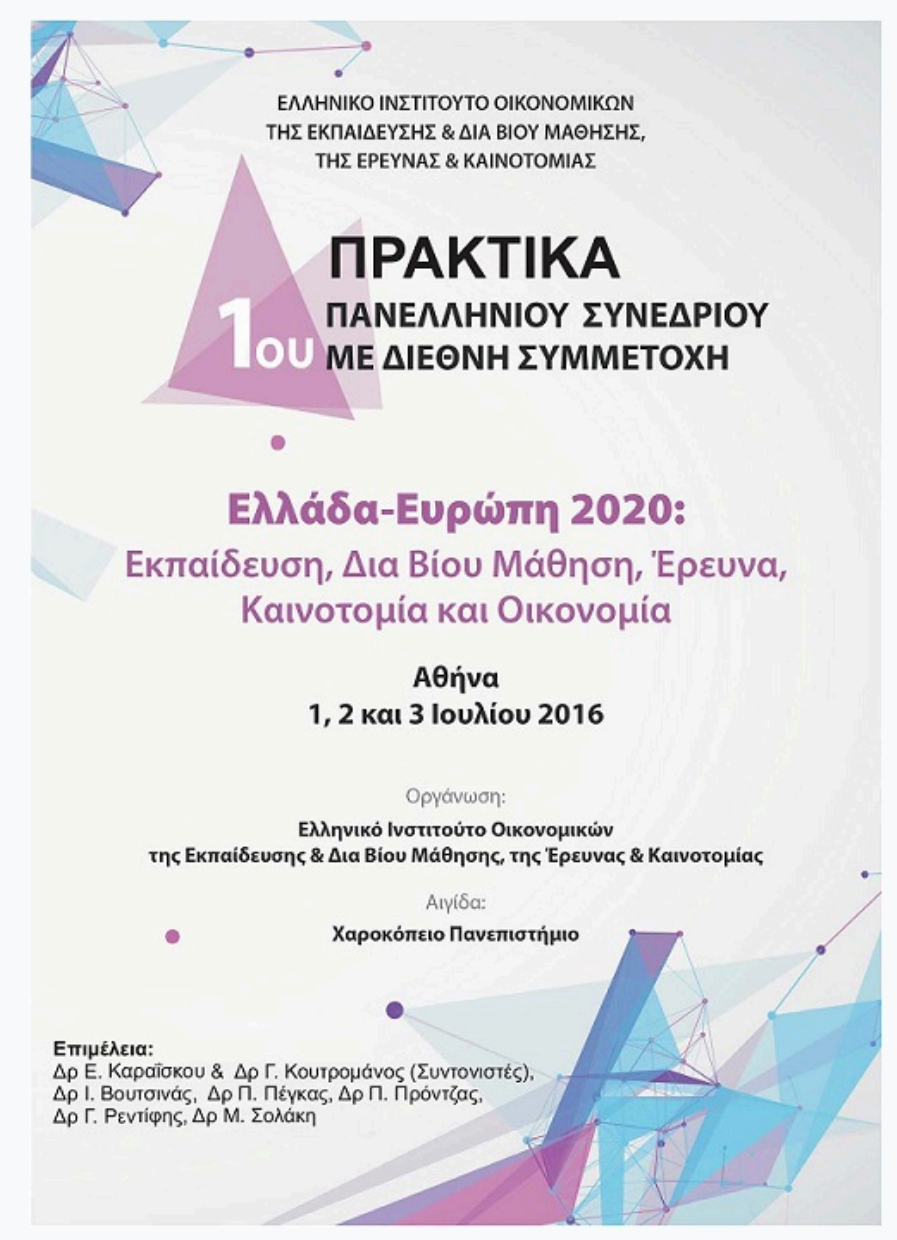

\section{Students' perceptions of barriers to entrepreneurship}

loannis K. Sitaridis, Fotis Kitsios

doi: $\underline{10.12681 / \text { elrie. } 815}$ 


\title{
Students' perceptions of barriers to entrepreneurship
}

\author{
Ioannis K. Sitaridis ${ }^{1}$, Fotis Kitsios ${ }^{2}$ \\ 1ysitar@gmail.com, ${ }^{2}$ kitsios@uom.gr
}

\begin{abstract}
Entrepreneurial activity and self-employment is considered a major motor of economic development. Intention is the individual's will to get involved into a specific behavior. Intentions are good predictors of actual behaviors according to the literature. Entrepreneurial intention is one's will to get involved into entrepreneurial activity and is considered a potential predictor of entrepreneurial startup. However, the constraints and barriers to entrepreneurship, act against one's intention, making the realization of the intentions into entrepreneurial action, difficult or even impossible. The engagement into entrepreneurial activity is constrained by the barriers faced by the entrepreneur during the startup or the development of the firm, as well as, perceived barriers faced by the prospective entrepreneur. Much light was shed upon the factors affecting entrepreneurial intentions and theories have been proposed. However, there is a lack of a systematic investigation in the area of barriers to entrepreneurship and how they affect entrepreneurial intentions. In this article, the barriers to entrepreneurship recorded in the literature are presented, along with some early insights of their impact on the entrepreneurial intention of university students in Greece.
\end{abstract}

Keywords: Barriers to entrepreneurship, Entrepreneurial intention, Self-employment constraints, Students

\section{Introduction}

Entrepreneurship is of such importance to a country's economy, that if one imagines the national economy as a battleship, then entrepreneurship is definitely the engine of that ship. Entrepreneurship, enables a variety of different people to pursuit economic success (Kuratko, 2011). Academic research suggests entrepreneurial intention as the major factor for the prediction of entrepreneurial behavior (Liñán \& Chen, 2009). Intention basically refers to the individuals will or belief to his or her entrepreneurial future. Intentions have been widely used as behavior predictors in the literature (Kolvereid \& Isaksen 2006; Krueger et al., 2000). According to Kolvereid \& Isaksen (2006), intentions to become self-employed determine actual entry into self-employment. Subsequently, entrepreneurial intention, has become a rapidly evolving field (Liñán \& Fayolle, 2015), with increasing number of articles approaching the subject both from theoretical and experimental perspectives. Nevertheless, when constraints or barriers exist, it is difficult to predict the realization of the intentions into an entrepreneurial action (Kolvereid \& Isaksen, 2006). The intentions are actually constrained by impeding forces and barriers throughout the entrepreneurial career path (Carayannis et al., 2003). According to Liñán \& Fayolle (2015), the effect of the barriers to entrepreneurial intention need to be investigated more thoroughly. A better understanding of the way the perception of entrepreneurial barriers interacts with intentions, will give us the means to dramatically improve entrepreneurial education. 


\section{Literature review}

In order to shed some light on the various aspects of barriers to entrepreneurship, acknowledged by previous research, we conducted a literature review. The methodology proposed by Webster \& Watson (2002) was adopted, because of the many benefits of their approach, namely:

- the search is not limited to one research methodology, one set of journals or geographic region,

- the approach to knowledge is concept centric,

- the research can be easily reproduced.

Studying the full texts of a primary set of articles (Kolvereid \& Isaksen 2006;Carayannis et al., 2003; Liñán \& Fayolle, 2015) we found the appropriate search terms. We searched the three databases of Scopus, Web of Science and EBSCO discovery services.

The keywords used were:

- $\quad$ "entrepre*" for entrepreneur, entrepreneurship, entrepreneurial etc.,

- "barrier*" for barrier or barriers,

- "constrain*" for constrain, constrains, constraint.

The keyword search was directed to the titles, abstracts and author keywords of articles written in English, and published in peer reviewed journals. The result was a pool of 1798 articles, from where we selected 247 articles addressing the issues of : "new firm", "firm creation", "firm formation", "business creation", "business formation", "establishment", "nascent", "new business", "new enterprise", "new venture" and "startup", after an abstract search. With a careful reading of abstracts we found 132 articles of potential relevance and another 15 articles resulted from backward search. After removing inaccessible and irrelevant articles, we ended up with 81 articles for full text study.

A number of 34 articles were discussing the issue of barriers to entrepreneurship under the scope of entrepreneurial intentions (EI), 19 of them including EI in their title. Furthermore, 24 articles were analyzing students' aspirations about self-employment, 19 articles were examining the perceptions of barriers of other individuals, and 18 articles were drawing data from various institutional organizations (including Global Entrepreneurship Monitor) on entrepreneurial constraints. Additionally, there were 11 articles examining barriers according to firm data and 7 text articles analyzing theoretical issues. Despite the extensive use of gender as a control variable in many articles, the majority of these articles included a few relative comments and only 11 articles addressed in depth the affect of gender on the perception of barriers.

In the following paragraphs, we record the barriers to entrepreneurship studied in these articles according to student data. In order to help the better understanding of the factors impeding entrepreneurial intentions, we tried to categorize those barriers by relevance, according to the literature. As our principal categorization, we chose the classification to Internal and External barriers (Sesen \& Pruett, 2014;Stamboulis \& Barlas 2014), which we found simple, and more general. All other categorizations proposed, are overlapping. 


\subsection{Internal Factors}

Personality traits like motivation (Iakovleva et al., 2014), courage and volition (Birdthistle, 2008), self-efficacy (Boyd \& Vozikis, 1994;Zhao, 2005), confidence and fear, either in financial terms (Finnerty \& Krzystofik, 1985) or in terms of risk avoidance (Giacomin et al., 2011; Singh Sandhu et al., 2011), are examined by many authors and are found to act either as drivers or as impediments to entrepreneurial intentions. For example, lack of motivation, lack of courage, lack of self-efficacy or confidence can act as personality constraints to one's engagement to self-employment. On the other hand fear and risk aversion are psychological factors having a definite negative effect of entrepreneurial intentions.

Educational skills and competence is another set of capabilities necessary to entrepreneurship. Lack of such capacities acts as a serious barrier towards the choice of an entrepreneurial career and a business startup (Birdthistle,2008; Robertson et al., 2003;Shinnar et al., 2009). Entrepreneurial education on the other hand, has a positive effect on the perception of barriers to entrepreneurship (Miller et al., 2009). Knowledge and skills are related to Entrepreneurial Self-Efficacy (Saleh, 2014), while experience and practice are also considered fundamental (Ribeiro et al., 2014) .

Personal attitude (Ajzen, 2002) towards entrepreneurial behavior refers to the degree of attractiveness of the idea of becoming an entrepreneur (Chang Hui-Chen et al., 2014). It is a measure of one's commitment to the target of establishing and running a new business (Kolvereid \& Isaksen, 2006). Negative attitude towards entrepreneurship was declared as a barrier to entrepreneurship by many authors (Ledyaeva et al., 2008;Singh Sandhu et al., 2011;Smith \& Beasley, 2011).

Finally, another parameter influencing the entrepreneurial intention indirectly through social norms, is gender. Gender, is affecting career choices through stereotypes, creating "gender appropriate occupations" (BarNir et al., 2011). Some authors refer to financial or start-up difficulties due to gender, because of discriminations towards women entrepreneurs (Akehurst et al., 2012) while others refer to lack of social support to entrepreneurial initiatives, due to gender stereotypes (Alvarez et al., 2011;Hackler \& Mayer, 2008).Thus, gender can be also considered a barrier to entrepreneurship under some circumstances.

The internal barriers to entrepreneurship referred above, are summarized in Table 1.

Table 1. Categorization of Internal barriers

\begin{tabular}{|c|c|c|}
\hline \multirow{10}{*}{$\begin{array}{l}\text { Internal } \\
\text { Barriers }\end{array}$} & \multirow[t]{5}{*}{ Personality } & Motivation Direction \\
\hline & & Lack of Courage Volition \\
\hline & & Self Efficacy \\
\hline & & Fear of Risk, Debt, Failure \\
\hline & & Lack of Confidence \\
\hline & \multirow{3}{*}{$\begin{array}{l}\text { Education \& } \\
\text { Competence }\end{array}$} & Knowledge Skills \\
\hline & & Abilities Competencies \\
\hline & & Experience \\
\hline & Attitude & Attitude towards Entrepreneurship \\
\hline & Gender & Gender Related \\
\hline
\end{tabular}




\subsection{External Factors}

Financing is probably the most crucial problem to entrepreneurship (Finnerty \& Krzystofik, 1985). The barrier is also identified by tertiary students in various researches, in the form of lack of initial capital, funding difficulty etc. (Birdthistle, 2008;Franke \& Lüthje, 2004;Ledyaeva et al., 2008; Shinnar et al., 2009; Shinnar et al., 2012; Smith \& Beasley, 2011). The perception of financial barriers is slightly differentiated between genders (Ribeiro et al., 2014) and between different levels of development (Giacomin et al. ,2011). Informal support, includes the lack of entrepreneurial role models, i.e. the presence of an entrepreneur in one's family environment, or in broader social structures, which can negatively influence the image of entrepreneurship in certain cultures (Pruett et al., 2009;Hawkins, 1993). Lack of social support (Baughn \& Neupert, 2003), and family commitments (Martins et al., 2004;Finnerty \& Krzystofik, 1985), are other informal factors that may act as barriers to entrepreneurship. Informal support is measured through Subjective-Social norm construct (Ajzen, 1991), which differentiates among different cultures (Pruett et al., 2009) and may act as a barrier under circumstances (Iakovleva et al., 2014). Formal support, includes institutional support, like funding, subsidies, consulting and service support, mostly referred by actual entrepreneurs (Akehurst et al., 2012). Young successful entrepreneurs declare their frustration according to the role of official support structures (Hulsink \& Koek, 2014), while also the majority of students asked, argue that, lack of institutional support is a major drawback to their entrepreneurial plans (Giacomin et al., 2011;Pruett et al., 2009;Smith \& Beasley, 2011;Sesen \& Pruett, 2014).

Resource constraints, including human resources (Ledyaeva et al., 2008) and infrastructures are vital to business startup and their lack is considered a barrier to entrepreneurship referred sometimes by students (Stamboulis \& Barlas, 2014), although they normally pertain actual entrepreneurs (Singh Sandhu et al., 2011).

Market related barriers, include the lack of social network (Singh Sandhu et al., 2011), lack of knowledge of the market (Shinnar et al., 2009), difficulty to contact or find customers (Ledyaeva et al., 2008;Birdthistle 2008;Stamboulis \& Barlas, 2014), tough competition (Franke \& Lüthje, 2004) and finally, lack of original ideas and perception of business opportunities (Franke \& Luthje, 2003;Miller et al., 2009;Stamboulis \& Barlas, 2014;Iakovleva et al., 2014;Pruett et al., 2009). Law and regulation constraints due to complexity or inconsistencies of the legal framework (Baughn \& Neupert, 2003), time consuming registration procedures (Iakovleva et al., 2014), frequently changing or tough labor regulations are frequently perceived as barriers to entrepreneurship by students (Franke \& Luthje, 2003; Franke \& Lüthje, 2004; Ledyaeva et al., 2008) and actual entrepreneurs (Choo \& Wong, 2006). Bureaucracy, administrative burden and difficulties to comply with regulations are obstacles related with the affairs between individuals and state services (Finnerty \& Krzystofik, 1985) which usually incorporate some frictions (Martins et al., 2004). This kind of barriers to entrepreneurship are perceived also by students affecting the entrepreneurial intentions (Franke \& Lüthje, 2004;Stamboulis \& Barlas, 2014) of those with lack of entrepreneurial role models (Ledyaeva et al., 2008) with minor differentiations between countries (Pruett et al., 2009). Corruption (Ledyaeva et al., 2008;Stamboulis \& Barlas, 2014) and taxation (Sesen \& Pruett, 2014) are also included in the same category of state related barriers.

Finally, hard reality is an overall perception of the economic and political situation, expressing general business climate, stability or uncertainty (Finnerty \& Krzystofik, 1985), influencing actual entrepreneurs plans as well as students entrepreneurial intentions (Sesen \& Pruett, 2014). 
The external barriers presented above are summarized in Table 2.

Table 2. Categorization of External Barriers

\begin{tabular}{|c|c|c|}
\hline \multirow{24}{*}{$\begin{array}{l}\text { External } \\
\text { Barriers }\end{array}$} & \multirow[t]{2}{*}{ Finance } & Funding Capital Borrowing Cos \\
\hline & & Irregular Income \\
\hline & \multirow[t]{3}{*}{ Informal Support } & Family commitmen \\
\hline & & Role Models \& family background \\
\hline & & Social Support - Subjective norms \\
\hline & \multirow[t]{2}{*}{ Formal Support } & Institutional Suppor \\
\hline & & Advisory Mentorship \\
\hline & \multirow[t]{2}{*}{ Resources } & Human Resources \\
\hline & & Infrastructures \\
\hline & \multirow[t]{5}{*}{ Market Related } & Networks \& Social Capital \\
\hline & & Market Information \& Knowledge \\
\hline & & Customer finding \\
\hline & & Market Pressure Tough Competition - Property Rights \\
\hline & & Right Idea - Opportunity Recognition \\
\hline & \multirow[t]{4}{*}{ Law \& Regulations } & Registration Procedure \\
\hline & & Regulations \\
\hline & & Legislation \& Structures \\
\hline & & Labor difficulties \\
\hline & \multirow[t]{4}{*}{ State Affairs } & Administrative burden \\
\hline & & Bureaucracy \\
\hline & & Corruption \\
\hline & & Tax \& Fisca \\
\hline & \multirow[t]{2}{*}{ Hard Reality } & Political Future Uncertainty \\
\hline & & Economic Climate Economic Indicators \\
\hline
\end{tabular}

\subsection{Empirical testing}

In order to investigate the intentions towards entrepreneurship and the perceptions of barriers of Greek students, we conducted a quantitative empirical research. Our sample was drawn among postgraduate students of applied informatics of University of Macedonia, in a random manner. The sample size $\mathrm{N}=81$ was relatively small because the research was still in progress by the time this article was written. The participating students answered an online questionnaire, which was sent to them by email.

The questionnaire consisted of a series of 22 items examining entrepreneurial intention (EI), motivation, perceptions of barriers to entrepreneurship and demographic data. The questions on EI were chosen from exceptional articles of the international academic literature on entrepreneurship, including measurement instruments concerning Entrepreneurial Intention, Motivation and Barriers to entrepreneurship. The selection criteria for each item was the level of correlation coefficients and reliability based on Cronbach's Alpha (where available). The questions were translated in Greek and for accuracy reasons a reverse translation was conducted by a professional English tutor (Harkness \& Schoua-Glusberg, 1998). Furthermore the appropriateness of the measures for each conceptual variable was confirmed by a panel of 
academic experts from entrepreneurship related disciplines. The final form of the questionnaire included improvements based on the recommendations of the experts. The questions are not included due to space constraints.

The sample characteristics are summarized in Table 3.

Table 3. Sample characteristics

\begin{tabular}{lcc}
\hline Student group & $\boldsymbol{n}$ & Percentage \\
\hline Gender & & \\
\hline Male & 43 & 53.1 \\
\hline Female & 38 & 46.9 \\
\hline Parent role model & & \\
\hline Yes & 41 & 50.6 \\
\hline No & 40 & 49.4 \\
\hline Age & & \\
\hline $18-24$ & 35 & 43.2 \\
\hline $25-34$ & 29 & 35.8 \\
\hline $35-44$ & 13 & 16.0 \\
\hline $45-55$ & 4 & 4.9 \\
\hline $\mathbf{N}$ & 81 & 100.0 \\
\hline
\end{tabular}

As can be seen from Table 3, the numbers of male and female students and the numbers of those having a parental role model in the family and those not, have no significant difference. A factor analysis was conducted on the data, to reveal any underlying latent factor structure. The Kaiser-Meyer-Olkin (KMO) Measure of Sampling was calculated, as a first step, in order to measure the degree of common variance among the observed variables. An almost "meritorious" value of 0.784 allows for a factor analysis to be conducted, with a substantial amount of variance expected (Table 4).

Table 4. The KMO and Bartlett's results

KMO and Bartlett's Test

\begin{tabular}{llr}
\hline Kaiser-Meyer-Olkin Measure of Sampling Adequacy. &, 784 \\
\hline Bartlett's Test of & Approx. Chi-Square & 916,736 \\
\cline { 2 - 3 } Sphericity & $\mathrm{df}$ & 171 \\
\cline { 2 - 3 } & Sig. &, 000 \\
\hline
\end{tabular}

Additionally, the null hypothesis that the intercorrelation matrix comes from a population in which the variables are non-collinear (i.e. an identity matrix) was rejected by the Bartlett's Test of Sphericity $(\mathrm{p}<0.001)$.

Table 5. Rotated factor matrix of the questionnaire items

\begin{tabular}{lcccccc}
\hline Item Id & \multicolumn{7}{c}{ Factor } \\
\hline & 1 & 2 & 3 & 4 & 5 & 6 \\
\hline \multicolumn{1}{r}{ Cronbach's Alpha } & 0,936 & 0,905 & 0,835 & 0,773 & 0,736 & 0,453 \\
\hline EI3 & 987 & & & & & \\
\hline
\end{tabular}




\begin{tabular}{|c|c|c|c|c|c|c|}
\hline EI5 & ,870 & & & & & \\
\hline EI4 & ,821 & & & & & \\
\hline EI2 & ,808 & & & & & \\
\hline EI1 &, 720 & & & & & \\
\hline M3 & & ,891 & & & & \\
\hline M1 & & ,844 & & & & \\
\hline M2 & & 827 & & & & \\
\hline B2_Experience & & 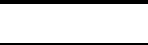 & ,815 & & & \\
\hline B1_Knowledge & & & ,809 & & & \\
\hline $\begin{array}{l}\text { B14_Knowledge } \\
\text { Details }\end{array}$ & & &, 786 & & & \\
\hline B9_Tax & & & & ,761 & & \\
\hline B11_Bureaucracy & & & & ,741 & & \\
\hline B8_Legislation & & & & ,701 & & \\
\hline B13_Access to Market & & & & & 871 & \\
\hline $\begin{array}{l}\text { B12_Hard } \\
\text { Competition }\end{array}$ & & & & & ,720 & \\
\hline B6_Bank Finance & & & & & &, 715 \\
\hline B7_General Finance & & & & & &, 440 \\
\hline $\begin{array}{l}\text { B5_Government } \\
\text { Finance }\end{array}$ & & & & & & ,353 \\
\hline Factor label & $\begin{array}{c}\text { Entrepre- } \\
\text { neurial } \\
\text { Intention }\end{array}$ & $\begin{array}{l}\text { Motiva- } \\
\text { tion }\end{array}$ & $\begin{array}{c}\text { Knowledg } \\
\text { e \& Skill } \\
\text { Constraints }\end{array}$ & $\begin{array}{l}\text { Regulation } \\
\text { s } \\
\text { Constraints }\end{array}$ & $\begin{array}{c}\text { Market } \\
\text { Constraints }\end{array}$ & $\begin{array}{c}\text { Funding } \\
\text { Constraints }\end{array}$ \\
\hline \multicolumn{7}{|c|}{$\begin{array}{l}\text { Extraction Method: Principal Axis Factoring. } \\
\text { Rotation Method: Promax with Kaiser Normalization. }\end{array}$} \\
\hline
\end{tabular}

Low communality values on items examining family conciliations, political and economic situation and formal support, forced us to exclude them from further testing because of, nonnormality of data. The factor extraction utilized the Principal Axis Factoring method for factor extraction, as it is superior compared to Maximum Likelihood (de Winter \& Dodou, 2012), for small samples and data showing non-normality as in our case. From the analysis, a number of six (6) factors emerged, with Eigenvalues greater than 1.0. A Promax rotation $(\mathrm{Kappa}=4)$ was used to improve the factor pattern, proposed for small non-normal samples (Costello \& Osborne, 1994). The total cumulative variance explained by the 6 factors sums up to a $64,9 \%$ of variance, which is acceptable for social sciences research (Sparkman et al., 1979). The results of the factor analysis are as shown in Table 5.

From Table 5, becomes evident that the first factor has loadings on items introduced by (Liñán \& Chen, 2009), referring to Entrepreneurial Intention, while the second factor has loadings on items referring to motivation towards entrepreneurship used by (C Hui-Chen et al., 2014). The rest of the factors represent barriers to entrepreneurship used in articles presented in the previous literature review. More specifically, the third factor has loadings on items referring to knowledge, experience and skills. The fourth factor has loadings on items related to law, taxation and bureaucracy, which can be categorized as external barriers due to regulation constraints. The fifth factor has loadings on market related constraints, namely access to market difficulties and hard competition. This factor has less than three items which could be considered as a weakness (Costello \& Osborne, 1994), but on the other hand it has an almost .8 mean of loadings which is strong enough and allows us to accept its validity. 
Finally the sixth factor has loadings on items related to funding constraints. The loadings of this last factor have an average of .5 which is marginally bearable.

The reliability of the various factors, expressing the degree of internal consistency, was evaluated using the Cronbach's Alpha coefficient, which is shown for every one of the factors in Table 5. All factors, except the sixth one (funding), have an Alpha coefficient greater than .7 , which reflects adequate reliability. The .45 value for the funding constraints is poor, which may be explained only by the small number of cases examined by our sample at this stage of the research.

Table 6. Descriptive statistics

\begin{tabular}{lcccc}
\hline Var Name & $N$ & Mean & $\begin{array}{c}\text { Std. } \\
\text { Deviation }\end{array}$ & Variance \\
\hline GENDER & 81 &, 53 &, 502 &, 252 \\
\hline AGE GROUP & 81 & 1,83 &, 877 &, 770 \\
\hline PARENTS (Role Models) & 81 &, 51 &, 503 &, 253 \\
\hline EI (Entrepreneurial Intention) & 81 &, 00 &, 98 &, 963 \\
\hline MO (Motivation) & 81 &, 00 &, 96 &, 921 \\
\hline KS (Knowledge \& Skills) & 81 &, 00 &, 94 &, 885 \\
\hline RC (Regulation Constraints) & 81 &, 00 &, 90 &, 808 \\
\hline MC (Market Constraints) & 81 &, 00 &, 89 &, 792 \\
\hline FC (Funding Constraints) & 81 &, 00 &, 83 &, 697 \\
\hline
\end{tabular}

Component scores were calculated finally by the factor analysis, using the regression method, to be used for further analysis (Kolvereid \& Isaksen, 2006). Control variables were also used for gender (Female $=0$, Male $=1)$, existence of role models in the family $($ Yes $=1$, No $=0)$ and age groups $(" 18-24 "=1, " 25-34 "=2, " 35-44 "=3$, "45-55"=4). The descriptive statistics of the control and score variables are illustrated in Table 6.

In Table 7, the Spearman's correlation matrix is illustrated between the six score variables. The correlation matrix offers a better observation of the dependencies between the six factors, namely Entrepreneurial Intention (EI), Motivation towards Entrepreneurship (MO), Knowledge and Skills (KS), Regulation Constraints (RC), Market Constraints (MC) and Financial Constraints (FC).

Table 7. Spearman's Correlations between score variables

\begin{tabular}{|c|c|c|c|c|c|c|c|}
\hline & & EI & MO & $\overline{\mathbf{K S}}$ & $\mathbf{R C}$ & $\mathrm{MC}$ & FC \\
\hline \multirow[t]{6}{*}{ Spearman's rho } & EI & 1,000 & & & & & \\
\hline & MO & $.639^{* * *}$ & 1,000 & & & & \\
\hline & & ,000 & & & & & \\
\hline & $\mathbf{K S}$ & $.583^{* * *}$ & $.289^{3 *}$ & 1,000 & & & \\
\hline & & ,000 & ,009 & & & & \\
\hline & $\mathbf{R C}$ & ,082 & $-.245^{*}$ &, 175 & 1,000 & & \\
\hline
\end{tabular}




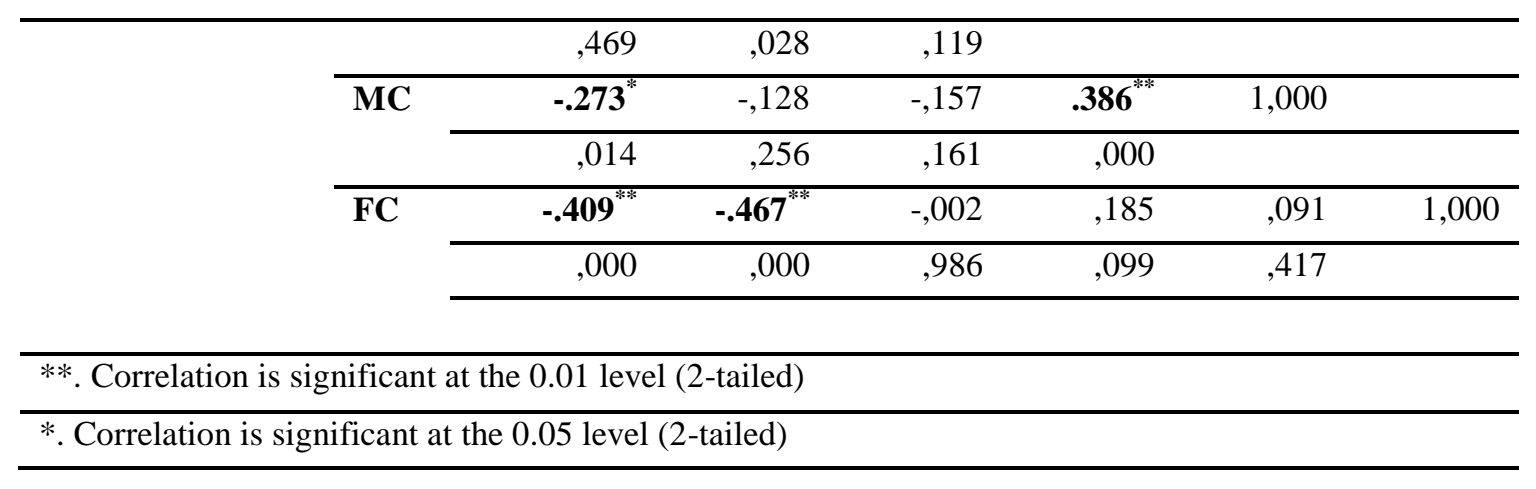

The correlation between Entrepreneurial Intention and Motivation, Knowledge and Skills, Market Constraints and Financial Constraints is statistically significant and in the expected direction. The correlation of EI and Regulation Constraints was not statistically significant. According to the correlation factors, the strongest influence on one's Entrepreneurial Intentions (.639) comes from his or her Motivation towards Entrepreneurship. Knowledge and Skills is the second influential factor (.583) positively affecting EI. Financial Constraints are the third factor with a negative influence this time (-.409) and Market Constraints rank as the fourth factor with a negative influence(-.273) also on EI. Unexpectedly the Regulations Constraints did not have a significant correlation to EI, nevertheless it had a negative correlation to Motivation (-.245), which is normally expected and a positive correlation to Market Constraints (.386) which is also an expected result. Furthermore, according to Motivation, there is a clear and strong negative influence from Financial Constraints (-.467) and a positive but mediocre influence from Knowledge and Skills (.289). All coefficients are significant at the .01 level, except for the EI-MC relation which is significant at the .05 level.

\section{Discussion}

As it is evident from the findings of the empirical research conducted so far, the perceived barriers to entrepreneurship, namely Financial and Market Constraints, have a significantly negative effect on the Entrepreneurial Intentions and the motives of students, towards entrepreneurship. On the other hand, personal Motivation and Knowledge, Skills and Experience according to our analysis, act as a powerful antidote against these barriers. These findings are consistent with previous research (Pruett et al., 2009;Sesen \& Pruett, 2014;Franke \& Luthje, 2003;Singh Sandhu et al., 2011). Due to lack of actual entrepreneurial experience students are expected to perceive the lack of knowledge experience and skills as a serious drawback in relation to entrepreneurial career. Additionally, students according to the literature are more influenced by internal personality barriers such as Motivation and Knowledge and Skills (Giacomin et al. 2011; Singh Sandhu et al., 2011). This fact becomes apparent from the absolute values of the correlation coefficients between barriers and Entrepreneurial Intentions, which are greater for internal barriers ( $\mathrm{MO}$ and $\mathrm{KS}$ ), in comparison to external barriers (FC,MC and RC). Financial Constraints are historically the most commonly referred barrier to entrepreneurship, and this fact may justify the higher correlation of this barrier to Entrepreneurial Intentions in comparison to the correlation of Market Constraints. Additionally, the perception of Financial Constraints as a barrier may be amplified by the economic recession in Greece. Finally, the Regulation Constraints barrier has no statistically significant effect. These results show that either students are not adequately 
informed about the actual conditions of the market, or they see a distorted image of the whole situation, through the lens of economic crisis.

\section{Conclusions}

The contribution of our work is an in depth examination of factors affecting entrepreneurship, and the systematic investigation in the area of barriers prohibiting self-employment. Furthermore, the first empirical data from our quantitative research gives valuable information about the perceptions of barriers by the want-to-be entrepreneurs university students. Stakeholders ought to take some precautions during the design of entrepreneurial courses and policies, in order to minimize the perception of entrepreneurial barriers and maximize motivating factors, such as education. The role of education on the one hand, should be to reorient students' career choices towards entrepreneurship, and additionally to make students capable of devising ways to overcome the conceivable barriers. This conclusion concerns especially Greece, where, not only the right motivations, knowledge and skills are required, but also, inspiring entrepreneurship educators that have the same innovative drive expected from entrepreneurship students (Kuratko, 2011). At the same time policy makers need to reduce the actual or perceived barriers through appropriate entrepreneurship support measures, in order to successfully overcome economic stagnation.

\section{Bibliography}

Ajzen, I. (2002) Perceived behavioral control, self-efficacy, locus of control, and the theory of planned behavior. Journal of Applied Social Psychology, 32(4), 665-683.

Ajzen, I. (1991) The theory of planned behavior. Organizational Behavior and Human Decision Processes, 50(2),179-211.

Akehurst, G., Simarro, E. \& Mas-Tur, A.(2012) Women entrepreneurship in small service firms: motivations, barriers and performance. The Service Industries Journal, 32(15), pp.2489-2505.

Alvarez, C., Urbano, D., Coduras, A., Ruiz-Navarro, J. (2011) Environmental conditions and entrepreneurial activity: a regional comparison in Spain, Journal of Small Business and Enterprise Development 18(1), 120-140.

BarNir, A., Watson, W.E. \& Hutchins, H.M. (2011) Mediation and Moderated Mediation in the Relationship Among Role Models, Self-Efficacy, Entrepreneurial Career Intention, and Gender. Journal of Applied Social Psychology, 41(2), 270-297.

Baughn, C. \& Neupert, K. (2003) Culture and national conditions facilitating entrepreneurial start-ups. Journal of International Entrepreneurship, 1(3), 313-330.

Birdthistle, N. (2008) An examination of tertiary students' desire to found an enterprise. $G$. Nabi, ed. Education + Training, 50(7), 552-567.

Boyd, N.G. \& Vozikis, G.S. (1994) The influence of self-efficacy on the development of entrepreneurial intentions and actions. Entrepreneurship Theory and Practice, 18, 63-63.

Carayannis, E.G., Evans, D. \& Hanson, M. (2003) A cross-cultural learning strategy for entrepreneurship education: Outline of key concepts and lessons learned from a 
comparative study of entrepreneurship students in France and the US. Technovation, 23(9),757-771.

Choo, S. \& Wong, M. (2006) Entrepreneurial intention: Triggers and barriers to new venture creations in Singapore. Singapore Management Review, 28(2), 47-64.

Costello, A.B. \& Osborne, J.W. (1994) Denpasar Declaration on Population and Development. Integration (Tokyo, Japan), (40),27-29.

Finnerty, J.F. \& Krzystofik, A.T. (1985) Barriers to Small Business Formation. Journal of Small Business Management, 23(3), 50-58.

Franke, N. \& Luthje, C. (2003) The "making" of an entrepreneur: testing a model of entrepreneurial intent among engineering students at MIT. $R$ and D Management, $33(2), 135-147$.

Franke, N. \& Lüthje, C. (2004) Entrepreneurial intentions of business students - A benchmarking study. International Journal of Innovation and Technology Management, 1(3), 269-288.

Giacomin, O. et al. (2011) Entrepreneurial intentions, motivations and barriers: Differences among American, Asian and European students. International Entrepreneurship and Management Journal, 7(2), 219-238.

Hackler, D. \& Mayer, H. (2008) Diversity, Entrepreneurship, and the Urban Environment. Journal of Urban Affairs, 30(3), 273-307.

Harkness, J. a \& Schoua-Glusberg, A. (1998) Questionnaires in Translation. ZUMANachrichten Spezial, (1), 87-126.

Hawkins, D.I. (1993) New business entrepreneurship in the Japanese economy. Journal of Business Venturing, 8(2), 137-150.

Hui-Chen, C., Kuen-Hung, T. \& Chen-Yi, P. (2014) The entrepreneurial process: an integrated model. International Entrepreneurship and Management Journal, 1-19.

Hulsink, W. \& Koek, D. (2014) The young, the fast and the furious: a study about the triggers and impediments of youth entrepreneurship. International Journal of Entrepreneurship and Innovation Management, 18(2/3), 182.

Iakovleva, T.A. et al. (2014) Comparison of perceived barriers to entrepreneurship in Eastern and Western European countries. International Journal of Entrepreneurship and Innovation Management, 18(2-3), 115-133.

Kolvereid, L. \& Isaksen, E. (2006) New business start-up and subsequent entry into selfemployment. Journal of Business Venturing, 21(6), 866-885.

Krueger, N.F., Reilly, M.D. \& Carsrud, A.L. (2000) Competing models of entrepreneurial intentions. Journal of Business Venturing, 15(5), pp.411-432.

Kuratko, D.F. (2011) Entrepreneurship theory, process, and practice in the 21st century. International Journal of Entrepreneurship and Small Business, 13(1), p.8.

Ledyaeva, S., Gustafsson-pesonen, A., Mochnikova, E., Vasilenko, D. (2008) Russian students' perceptions of entrepreneurship. results of a survey in three St. Petersburg universities. Entrepreneurship development - project 2. Helsinki School of Economics, 83.

Liñán, F. \& Chen, Y.-W. (2009) Development and cross-cultural application of a specific instrument to measure entrepreneurial intentions. Entrepreneurship: Theory and Practice, 33(3), 593-617. 
Liñán, F. \& Fayolle, A. (2015) A systematic literature review on entrepreneurial intentions: citation, thematic analyses, and research agenda. International Entrepreneurship and Management Journal, 11(4), 907-933.

Martins, S., Couchi, C., Parat, L., Carmine, F., Doneddu, R., Salmon, M. (2004) Barriers to entrepreneurship and business creation, European Entrepreneurship Cooperation Observatory.

Miller, B.K., Bell, J.D., Palmer, M., Gonzalez, A. (2009) Predictors of Entrepreneurial Intentions: a Quasi-Experiment Comparing Students Enrolled in Introductory Management and Entrepreneurship Classes. Journal of Business \& Entrepreneurship, 21(2), 39.

Pruett, M., Shinnar, R., Toney, B., Llopis, F., Fox, J. (2009) Explaining entrepreneurial intentions of university students: a cross-cultural study. International Journal of Entrepreneurial Behaviour \& Research, 15(6), 571-594.

Ribeiro, M.I.B., Fernandes, A.J.G. \& De S. Diniz, F.J.L. (2014) Entrepreneurial potential of Portuguese agriculture higher education students: A case from the alto trás-osmontes region, Portugal. Economy of Region, (2), 212-220.

Robertson, M., Collins, A., Medeira, N., Slater, J. (2003) Barriers to start-up and their effect on aspirant entrepreneurs. Education + Training, 45(6), 308-316.

Saleh, H.A. (2014) The Perceptions of the Lebanese Students of Choosing their Career in Entrepreneurship. Jordan Journal Business Administration, 10, 333.

Sesen, H. \& Pruett, M. (2014) The Impact of Education, Economy and Culture on Entrepreneurial Motives, Barriers and Intentions: A Comparative Study of the United States and Turkey. Journal of Entrepreneurship, 23(2), 231-261.

Shinnar, R., Pruett, M. \& Toney, B. (2009) Entrepreneurship Education: Attitudes across Campus. Journal of Education for Business, 84(3), 151-159.

Shinnar, R.S., Giacomin, O. \& Janssen, F. (2012) Entrepreneurial Perceptions and Intentions: The Role of Gender and Culture. Entrepreneurship Theory and Practice, 36(3), 465-493.

Singh Sandhu, M., Fahmi Sidique, S. \& Riaz, S. (2011) Entrepreneurship barriers and entrepreneurial inclination among Malaysian postgraduate students. International Journal of Entrepreneurial Behavior \& Research, 17(4), 428-449.

Smith, K. \& Beasley, M. (2011) Graduate entrepreneurs: intentions, barriers and solutions Business - ProQuest H. Matlay, ed. Education + Training, 53(8/9), 722-740.

Sparkman, R.M., Hair, J.F., Anderson, R.E., Tatham, R.L., Grablowsky, B.J. (1979) Multivariate Data Analysis with Readings, Journal of Marketing Research, 16, 437.

Stamboulis, Y. \& Barlas, A. (2014) Entrepreneurship education impact on student attitudes. The International Journal of Management Education, 12(3), 365-373.

Webster, J. \& Watson, R.T. (2002) Analyzing the Past to Prepare for the Future: Writing a Literature Review. MIS Quarterly, 26(2), xiii - xxiii.

de Winter, J.C.F. \& Dodou, D. (2012) Factor recovery by principal axis factoring and maximum likelihood factor analysis as a function of factor pattern and sample size. Journal of Applied Statistics, 39(4), 695-710.

Zhao, F. (2005) Exploring the synergy between entrepreneurship and innovation. International Journal of Entrepreneurial Behavior \& Research, 11(1), 25-41. 